\title{
24-hour near-infrared spectroscopy monitoring of acute ischaemic stroke patients undergoing thrombolysis or thrombectomy: a pilot study
}

Ádám Annus $\mathrm{MD}^{1}$, András Nagy $\mathrm{MD}^{2}$, László Vécsei MD, $\mathrm{PhD}, \mathrm{DSc}^{1,3}$, Péter Klivényi MD, $\mathrm{PhD}, \mathrm{DSc}^{1}$

\author{
Affiliations: \\ ${ }^{1}$ Department of Neurology, Albert Szent-Györgyi Clinical Center, University of Szeged, H- \\ 6725 Szeged, Semmelweis u. 6, Hungary \\ ${ }^{2}$ Department of Radiology, Albert Szent-Györgyi Clinical Center, University of Szeged, H- \\ 6725 Szeged, Semmelweis u. 6, Hungary \\ ${ }^{3}$ MTA-SZTE Neuroscience Research Group, H-6725 Szeged, Semmelweis u. 6, Hungary \\ E-mail: annus.adam@med.u-szeged.hu, andras.nagy@med.u-szeged.hu,
} vecsei.laszlo@med.u-szeged.hu,klivenyi.peter@med.u-szeged.hu

Shortened title: NIRS monitoring in acute ischaemic stroke.

Grant support: project GINOP (2.3.2-15- 2016-00048.).

\section{Corresponding author:}

Péter Klivényi MD, $\mathrm{PhD}$, DSc

Department of Neurology, Faculty of Medicine, University of Szeged,

Semmelweis u. 6,

H-6725 Szeged,

Hungary

Tel:+36 62545351

Fax:+36 62545597

E-mail: klivenyi.peter@med.u-szeged.hu 


\begin{abstract}
Introduction

Monitoring of acute ischaemic stroke patients during thrombolysis or thrombectomy is based mostly on frequent physical examinations, since no objective measurement of cerebrovascular haemodynamics is available in routine clinical practice. Near-infrared spectroscopy (NIRS) is a bed-side, non-invasive assessment tool that could help monitor these patients and potentially guide therapeutic interventions. Our goal in this pilot study was to investigate whether NIRS is a suitable method to monitor leptomeningeal collateral circulation via changes in cortical oxygen saturation in the first 24 hours of acute ischaemic stroke.
\end{abstract}

\title{
Patients and methods
}

Our study included 5 patients with acute anterior circulation infarcts. All patients received thrombolytic therapy and one had thrombectomy. 24-hour continuous NIRS monitoring was performed on all participants.

\section{Results}

We aimed to give a detailed description of each NIRS recording and explain how the observed findings could correlate with changes in anterior watershed territory collateral circulation and clinical outcome.

\section{Conclusion}

Our pilot study supports the use of NIRS monitoring in acute ischaemic stroke. We believe that this technique could provide real-time information on the dynamic changes of leptomeningeal collateral circulation and help monitor the effects of thrombolysis and thrombectomy.

Keywords: near-infrared spectroscopy (NIRS), ischaemic stroke, thrombolysis, collateral circulation. 


\section{Introduction}

Intravenous administration of recombinant tissue plasminogen activator (rt-PA) is the treatment of choice in eligible acute ischaemic stroke patients who arrive to the hospital within the therapeutic time window (1). If large vessel occlusion is present, mechanical thrombectomy should be performed as well. Monitoring of patients during these procedures is based mostly on frequent physical examinations. For the time being, no objective measurement of the patients' cerebrovascular haemodynamics is used in routine clinical practice. Near-infrared spectroscopy (NIRS) is a bed-side, non-invasive, continuous, real time assessment tool which could help monitor patients with acute ischaemic stroke. It is most commonly used during cardiac surgery and carotid endarterectomy to detect and prevent cortical desaturations which might lead to permanent neurological sequelae (2). To our knowledge, only a few observational and pilot studies have been published that investigated the potential of NIRS monitoring during acute ischaemic stroke (3-6).

NIRS utilizes a light source which emits photons in the near-infrared range (700-1100 $\mathrm{nm})$. These photons can penetrate thought the skull and a few centimetres deep into the brain tissue. The emitted light is partly redirected, scattered and absorbed. The absorption spectrum of oxyhaemoglobin $\left(\mathrm{Hb}_{\text {oxy }}\right)$ and deoxyhaemoglobin $\left(\mathrm{Hb}_{\text {deoxy }}\right.$ is different at various wavelengths(7). This difference allows for calculation of $\mathrm{Hb}_{\text {oxy }}$ and $\mathrm{Hb}_{\text {deoxy }}$ concentrations based on the difference in intensity of emitted and received light, using the Beer-Lambert equation:

$$
A=\lg \frac{I_{0}}{I}=\varepsilon \times c \times l
$$

(A: absorption, $\mathrm{I}_{0}$ : intensity of emitted light, $\mathrm{I}$ : intensity of received light, $\varepsilon$ : absorption coefficient, c: concentration, l: photon pathlenght).

Total haemoglobin $\left(\mathrm{Hb}_{\mathrm{T}}\right)$ concentration equals the sum of $\mathrm{Hb}_{\text {oxy }}$ and $\mathrm{Hb}_{\text {deoxy }}$ concentrations and is proportional to cerebral blood volume (CBV) (8). Therefore NIRS can be used to measure cortical blood oxygenation/saturation (the fraction of $\mathrm{Hb}_{\text {oxy }}$ relative to $\mathrm{Hb}_{\mathrm{T}}$ ) and serve as an indicator for the balance between cerebral oxygen delivery and consumption $(2,9)$. Mean cortical saturation measured with NIRS comprises of approximately $70 \%$ venous and $30 \%$ arterial blood (7). It has been established that the relative change in regional $\mathrm{O}_{2}$ saturation $\left(\mathrm{rSO}_{2}\right)$ and not the absolute $\mathrm{rSO}_{2}$ is considered as a marker of cerebral haemodynamics, since absolute values show great interindividual variability $(10,11)$. Other limitations of NIRS are environmental and individual features that influence absolute $\mathrm{rSO}_{2}$ 
values. These features are summarized in Table $1(3,12)$. Combined effect of the listed factors can sometimes make the interpretation of NIRS measurements uncertain.

It has been established that collateral circulation plays a pivotal role in reducing progression of ischaemic brain damage (13). Patients with good collaterals develop smaller infarcts, respond better to mechanical thrombectomy, show better clinical outcome and have a lesser chance for haemorrhagic transformation after thrombolysis (14-16). However, real-time assessment of collateral circulation in the setting of acute ischaemic stroke is lacking. We know from multimodal MRI studies that augmented CBV, preserved cerebral blood flow (CBF) and delayed mean transit time (MTT) imply the presence of collateral flow (17). Taussky et al. showed a linear correlation between $\mathrm{rSO}_{2}$ and $\mathrm{CBF}$ measured with CT perfusion (18). Therefore, since $\mathrm{CBV}$ and $\mathrm{CBF}$ correlates with $\mathrm{rSO}_{2}$ values, our goal in this pilot study was to investigate whether NIRS is a suitable method to monitor anterior watershed territory leptomeningeal collateral circulation via changes in cortical oxygenation during thrombolysis and thrombectomy. Due to the small sample size of our pilot study, we could not draw statistical conclusions. Instead, we aimed to give detailed analysis of the 5 NIRS recordings and explain how these findings could correlate with cerebrovascular haemodynamics and clinical picture.

\section{Patients and methods}

The study was approved by an independent ethics committee (University of Szeged, Faculty of Medicine, Ethics Committee, ID: 211/2016-SZTE). All patients or first degree relatives gave written informed consent prior to NIRS monitoring. Our study population included 5 acute stroke patients who had left sided anterior circulation infarcts. Detailed patient characteristics are highlighted in Table 2. All participants received alteplase as recommended by the 2018 AHA/ASA acute ischaemic stroke guideline (1). One patient also had mechanical thrombectomy due to left M1 occlusion (Patient 3). INVOS ${ }^{\text {TM }}$ 5100C Cerebral/Somatic Oximeter (Medtronic, Minneapolis, MN, USA) was used for 24-hour continuous monitoring. Application of the NIRS sensors did not delay the start of thrombolysis. The sensors were placed over bilateral frontal areas, as recommended by the manufacturer. The studied brain areas correspond to the anterior watershed territories. Baseline $\mathrm{rSO}_{2}$ was measured before the initiation of intravenous rt-PA. $\mathrm{rSO}_{2}$ measurements were made approximately every 30 seconds. We analysed the 5 minute average $\mathrm{rSO}_{2}$ values registered at the start of thrombolysis 
and also 1 hour, 6 hours, 12 hours, 18 hours and 24 hours after the initiation of alteplase treatment. Interhemispheric $\mathrm{rSO}_{2}$ difference $\left(\mathrm{IH} \Delta \mathrm{rSO}_{2}\right)$ was calculated as $\mathrm{rSO}_{2}$ on the affected side minus $\mathrm{rSO}_{2}$ measured above the contralateral side. Based on previous articles, $4 \%$ change in $\mathrm{rSO}_{2}$ value, and $2 \%$ change in $\mathrm{IH} \Delta \mathrm{rSO}_{2}$ was considered significant $(5,19)$. Simultaneously, blood pressure, peripheral $\mathrm{O}_{2}$ saturation $\left(\mathrm{SpO}_{2}\right)$, heart rate and electrocardiography were also monitored. The patients' $\mathrm{SpO}_{2}$ was above $92 \%$ while breathing ambient air, therefore they did not receive $\mathrm{O}_{2}$ supplementation during the study period. The only exception was Patient 3 who underwent thrombectomy. He was intubated because he could not cooperate to the procedure due to severe aphasia. The patients' clinical outcome was assessed with the National Institutes of Health Stroke Scale (NIHSS) and modified Rankin scale (mRS). A mRS score of 0-2 at 90 days was considered as good functional outcome. If large vessel occlusion (LVO) was present, collateral circulation on imaging was assessed by a neuroradiologist using a 3 grade scale (good-intermediate-poor). Initially, Patients 1-3 had CT angiography (CTA) and Patients 4-5 had MR angiography - time of flight (MRA-TOF) imaging. Figure 1 shows CT and MRI scans approximately 24 hours after thrombolysis for each patient.

\section{Results}

\subsection{Descriptive analysis of each patients' NIRS recordings}

Patient 1 suffered a left middle cerebral artery (MCA) territory stroke due to M2 occlusion. Collateral circulation was good based on CTA. During NIRS monitoring, no relevant $\mathrm{rSO}_{2}$ difference was observed between the two hemispheres ( $\mathrm{IH} \Delta \mathrm{rSO}_{2}$ was between $-2 \%$ and $0 \%$ ). $\mathrm{rSO}_{2}$ values were quite stable on both sides. The patient had a good clinical outcome at 3 months.

Patient 2 had clinical signs of left hemispheric stroke. CTA revealed a left internal carotid artery (ICA) occlusion. Good collaterals were detected on CTA and $\mathrm{rSO}_{2}$ absolute values were higher above the ipsilateral side (average $\mathrm{IH} \Delta \mathrm{rSO}_{2}$ was $3 \%$ ). $\mathrm{rSO} 2$ levels gradually rose in the first 12 hours on both sides. This might indicate subtle increase in CBV and CBF in the leptomeningeal collaterals. The patient's NIHSS score decreased in the first few days and eventually showed good clinical outcome at 3 months.

Patient 3 had a left M1 occlusion and underwent endovascular thrombectomy after thrombolysis. Collaterals were graded as intermediate on CTA. Initially, a significant $\mathrm{IH} \Delta \mathrm{rSO}_{2}$ was observed. The affected side had a lower absolute $\mathrm{rSO}_{2}$ value (55\% vs.63\%). 
This difference did not change after thrombolysis ( $1 \mathrm{~h}$ post thrombolysis $\mathrm{IH} \Delta \mathrm{rSO}_{2}$ was $-7 \%$ ). However, after thrombectomy there was a significant increase in $\mathrm{rSO}_{2}$ on the ipsilateral side and consequently $\mathrm{IH} \Delta \mathrm{rSO}_{2}$ substantially decreased. $\mathrm{IH} \Delta \mathrm{rSO}_{2}$ absolute values even became positive after 12 hours. These findings possibly indicate that NIRS sensors were either placed above ischaemic territory or the leptomeningeal collateral circulation was insufficient. As expected from the NIRS recording of the first 24 hours, the patient's recovery went well (mRS 1 at 90 days).

Patient 4 was the only participant who did not achieve good functional outcome at 90 days (mRS was 3). She suffered a left MCA territory infarction, MRA-TOF imaging did not show LVO. Before thrombolysis, absolute $\mathrm{rSO}_{2}$ was significantly higher on the affected side $(69 \%$ vs. $61 \%$ ). After 1 hour, a marked increase of $\mathrm{rSO}_{2}$ was observed above both hemispheres $\left(+9 \%, \mathrm{IH} \Delta \mathrm{rSO}_{2}\right.$ remained $\left.8 \%\right)$. $\mathrm{IH} \Delta \mathrm{rSO}_{2}$ then steeply decreased to $-2 \%$ at 12 hours. The patient's NIHSS score worsened. Control CT scan revealed a left striatocapsular infarct. The striatocapsular territory is supplied by perforator arteries stemming from the proximal part of M1 and does not have collateral circulation (20). Since $\mathrm{rSO}_{2}$ increased similarly above both hemispheres in the first hour, it is possible that the ischaemic insult provoked an increase in global cerebral perfusion.

Patient 5 had markedly elevated $\mathrm{rSO}_{2}$ values above the ipsilateral hemisphere ( $82 \%$ vs 69\%). The significantly high $\mathrm{IH} \Delta \mathrm{rSO}_{2}$ was possibly a consequence of chronic right ICA occlusion which led to long-term, effective Willisian collateralization and consequent enlargement of left ICA, MCA and anterior cerebral artery (ACA) (Figure 1/f). Increased blood flow in the left MCA and ACA could explains the high $\mathrm{rSO}_{2}$ values above the ipsilateral watershed area, implying well-developed leptomeningeal collaterals. The $\mathrm{IH} \Delta \mathrm{rSO}_{2}$ value remained high throughout the 24-hour monitoring. The patient had a good functional outcome at 3 months.

Data of NIRS recordings and diagrams are found in the Supplementary material.

\subsection{Analysis of combined results}

The initial $\mathrm{rSO}_{2}$ above the affected hemispheres showed greater variability compared to the contralateral sides. Patient 5 's results might have led to bias, therefore we only examined the first 4 patients' results. Still, the difference in variability remained significant, which was most prominent in the first 12 hours. This finding probably reflects impaired autoregulation 
on the affected side. Graphs demonstrating $\mathrm{rSO}_{2}$ variability are found in the Supplementary material.

\section{Discussion}

Most of the previous studies that used NIRS in the setting of acute ischaemic stroke aimed to study the oxygenation of ischaemic brain area. Instead, we tried to investigate whether NIRS is feasible in evaluating leptomeningeal collaterals located at the anterior watershed areas. We believe, that a good example for our hypothesis is the case of Patient 5. Due to a chronic right ICA occlusion, we measured significantly higher $\mathrm{rSO}_{2}$ values above the left hemisphere. The explanation of this finding is possibly the increased blood flow in the left ICA, MCA and ACA which provides adequate blood perfusion to both hemispheres through the circle of Willis. Long-term increased flow led to enlargement of these vessels and subsequently welldeveloped leptomeningeal collateral circulation in the monitored hemisphere.

Ritzenthaler et al. performed 24-hour NIRS monitoring in 17 acute stroke patients who underwent mechanical thrombectomy (4). All their patients had lower absolute $\mathrm{rSO}_{2}$ values above the affected hemisphere. They did not find a significant relationship between initial ipsilateral $\mathrm{rSO}_{2}$ and collateral circulation (assessed with American Society of Interventional and Therapeutic Neuroradiology Collateral Flow Grading scale, ASITN). Explanations behind their finding might be that NIRS sensors were above ischaemic territory or the leptomeningeal collateral circulation was insufficient in all participants. Since the authors reported patients with ASITN score of more than 3 (indicating good collateral flow), the latter explanation seems unlikely. In our study, Patient 3 demonstrated a similar NIRS trend to those cases published in Ritzenthaler's article. After successful recanalization, $\mathrm{IH} \Delta \mathrm{rSO}_{2}$ significantly decreased. Patient 2 had left ICA occlusion, but still had higher $\mathrm{rSO}_{2}$ on the ipsilateral side possibly due to well-developed leptomeningeal collaterals.

In another study, NIRS monitoring was also used during thrombectomy in 43 acute ischaemic stroke patient (3). Hametner et al. reported that absolute values of median $\mathrm{IH} \Delta \mathrm{rSO}_{2}$, measured at the end of thrombectomy, were significantly lower in patients who died by 90 days. In addition, patients whose variability in rSO2 values were lower, showed significantly worse 90-day outcomes (mRS score 3-6). Due to the small sample size of our study, we could not draw significant statistical correlations related to NIRS parameters and clinical outcome. Instead, we aimed to give individual descriptions of each patients' monitoring. 
Damian and Schlosser investigated patients with MCA occlusions who had consequent brain oedema (19). NIRS monitoring was performed in the subacute phase of stroke (at least 12 hours, but within 4 days after the ictus). Interestingly, 22 out of 24 patients had higher absolute $\mathrm{rSO}_{2}$ values above the ipsilateral frontal area. These data are quite the opposite of that published by Ritzenthaler et al. We hypothesize that this difference is because the measurements were made at different time points (subacute vs. acute phase of stroke). It is possible, that the observed positive absolute $\mathrm{IH} \Delta \mathrm{rSO}_{2}$ values in Damien and Schlosser's study reflects increased compensatory leptomeningeal collateral circulation, which developed on the affected side a few days after the cerebrovascular insult. The article reported good clinical outcome (Glasgow Outcome Scale 3-4) in cases where average $\mathrm{IH} \Delta \mathrm{rSO}_{2}$ values increased over time. Outcomes were assessed between 6-24 weeks, after rehabilitation. In all 5 cases, where the initial $\mathrm{IH} \Delta \mathrm{rSO}_{2}$ decreased, the patients died. Another important finding of the study was that clinical signs of progressing brain oedema and unfavourable $\mathrm{rSO}_{2}$ changes were reversible in some cases by hemicraniectomy, hyperventilation, hypothermia or improved systemic perfusion (19). Therefore, correct interpretation of NIRS monitoring could guide therapeutic interventions. Previous studies showed, that decrease in systemic blood pressure and/or peripheral oxygen saturation $\left(\mathrm{SpO}_{2}\right)$ correlates well with a drop in $\mathrm{rSO}_{2}(3,5)$. We believe, that NIRS parameters can guide clinicians in finding the target blood pressure and $\mathrm{SpO}_{2}$ values of each individual patient. For example, some patients with acute ICA occlusion could benefit from increasing blood pressure to maintain adequate collateral circulation until thrombectomy can be performed to achieve recanalization. A preclinical study investigated this concept and found that mild induced hypertension increased cortical collateral blood flow and significantly reduced infarct volume in mice with transient distal MCA occlusion (21).

NIRS monitoring would provide additional information if more sensors were placed over the cerebral hemispheres. This way, $\mathrm{rSO}_{2}$ could be simultaneously measured over the ischaemic territory and watershed areas. Rummel et al. used multichannel NIRS monitoring during transient balloon occlusion of cerebral arteries (8). They demonstrated that different $\mathrm{rSO}_{2}$ changes are observed over the ischaemic core and watershed areas during transient LVOs due to haemodynamic changes in collateral flow. Moreau et al. also applied multichannel NIRS monitoring in 5 acute ischaemic stroke patient who had LVO. The sensors were placed over the frontal, parasagittal frontal, Rolandic sulcus, Broca and Wernicke areas of the brain (12). The symptom onset to monitoring time was within 9 hours. They found that, at least one region of the infarcted hemisphere showed reduced $\mathrm{rSO}_{2}$ values compared to the unaffected, 
contralateral side. One of their patient's suffered a haemorrhagic transformation a few days after the ischaemic event. Not surprisingly, $\mathrm{rSO}_{2}$ values were significantly higher above the affected hemisphere compared to the contralateral side. This finding is probably explained by the presence of still highly oxygenated blood within the brain tissue (12).

Table 3 highlights the most important findings of previous NIRS studies.

In summary, the results of our pilot study support the use of NIRS monitoring in the setting of acute ischaemic stroke. We believe that this technique could provide valuable information on the state of leptomeningeal collaterals and help monitor the effects of thrombolysis and thrombectomy. In addition, $\mathrm{rSO}_{2}$ values could guide individual management of patients' blood pressure and oxygen supplementation to widen the therapeutic time window for recanalization (17). However, future studies, preferably with multichannel NIRS monitoring are warranted to gain further information on the relation between leptomeningeal collaterals, ischaemic territory and $\mathrm{rSO}_{2}$ absolute values and trends.

\section{Acknowledgements}

This work was supported by the project GINOP (2.3.2-15- 2016-00048.), and the MTA-SZTE Neuroscience Research Group of the Hungarian Academy of Sciences and the University of Szeged. We are grateful for the help of the Department of Anaesthesiology and Intensive Therapy for allowing us to use the INVOS ${ }^{\mathrm{TM}} 5100 \mathrm{C}$ Cerebral/Somatic Oximeter.

\section{Conflicts of interest}

The authors declare that they have no conflict of interest. 


\section{References}

1. Powers WJ, Rabinstein AA, Ackerson T, Adeoye OM, Bambakidis NC, Becker K, et al. 2018 Guidelines for the Early Management of Patients With Acute Ischemic Stroke: A Guideline for Healthcare Professionals From the American Heart Association/American Stroke Association. Stroke. 2018;49(3):e46-e110.

2. Scheeren TW, Schober P, Schwarte LA. Monitoring tissue oxygenation by near infrared spectroscopy (NIRS): background and current applications. Journal of clinical monitoring and computing. 2012;26(4):279-87.

3. Hametner C, Stanarcevic P, Stampfl S, Rohde S, Veltkamp R, Bosel J. Noninvasive cerebral oximetry during endovascular therapy for acute ischemic stroke: an observational study. Journal of cerebral blood flow and metabolism : official journal of the International Society of Cerebral Blood Flow and Metabolism. 2015;35(11):1722-8.

4. Ritzenthaler T, Cho TH, Mechtouff L, Ong E, Turjman F, Robinson P, et al. Cerebral NearInfrared Spectroscopy: A Potential Approach for Thrombectomy Monitoring. Stroke. 2017;48(12):3390-2.

5. Aries MJ, Coumou AD, Elting JW, van der Harst JJ, Kremer BP, Vroomen PC. Near infrared spectroscopy for the detection of desaturations in vulnerable ischemic brain tissue: a pilot study at the stroke unit bedside. Stroke. 2012;43(4):1134-6.

6. Terborg C, Bramer S, Harscher S, Simon M, Witte OW. Bedside assessment of cerebral perfusion reductions in patients with acute ischaemic stroke by near-infrared spectroscopy and indocyanine green. Journal of neurology, neurosurgery, and psychiatry. 2004;75(1):38-42.

7. Murkin JM, Arango M. Near-infrared spectroscopy as an index of brain and tissue oxygenation. British journal of anaesthesia. 2009;103 Suppl 1:i3-13.

8. Rummel C, Zubler C, Schroth G, Gralla J, Hsieh K, Abela E, et al. Monitoring cerebral oxygenation during balloon occlusion with multichannel NIRS. Journal of cerebral blood flow and metabolism : official journal of the International Society of Cerebral Blood Flow and Metabolism. 2014;34(2):347-56.

9. Obrig H. NIRS in clinical neurology - a 'promising' tool? Neurolmage. 2014;85 Pt 1:535-46.

10. Misra M, Stark J, Dujovny M, Widman R, Ausman JI. Transcranial cerebral oximetry in random normal subjects. Neurological research. 1998;20(2):137-41.

11. Mille T, Tachimiri ME, Klersy C, Ticozzelli G, Bellinzona G, Blangetti I, et al. Near infrared spectroscopy monitoring during carotid endarterectomy: which threshold value is critical? European journal of vascular and endovascular surgery : the official journal of the European Society for Vascular Surgery. 2004;27(6):646-50.

12. Moreau F, Yang R, Nambiar V, Demchuk AM, Dunn JF. Near-infrared measurements of brain oxygenation in stroke. Neurophotonics. 2016;3(3):031403.

13. Ginsberg MD. The cerebral collateral circulation: Relevance to pathophysiology and treatment of stroke. Neuropharmacology. 2018;134(Pt B):280-92.

14. Menon BK, Smith EE, Modi J, Patel SK, Bhatia R, Watson TW, et al. Regional leptomeningeal score on $\mathrm{CT}$ angiography predicts clinical and imaging outcomes in patients with acute anterior circulation occlusions. AJNR American journal of neuroradiology. 2011;32(9):1640-5.

15. van den Wijngaard IR, Boiten J, Holswilder G, Algra A, Dippel DW, Velthuis BK, et al. Impact of Collateral Status Evaluated by Dynamic Computed Tomographic Angiography on Clinical Outcome in Patients With Ischemic Stroke. Stroke. 2015;46(12):3398-404.

16. Yeo LL, Paliwal P, Low AF, Tay EL, Gopinathan A, Nadarajah M, et al. How temporal evolution of intracranial collaterals in acute stroke affects clinical outcomes. Neurology. 2016;86(5):434-41.

17. Liebeskind DS. Collaterals in acute stroke: beyond the clot. Neuroimaging clinics of North America. 2005;15(3):553-73, x.

18. Taussky P, O'Neal B, Daugherty WP, Luke S, Thorpe D, Pooley RA, et al. Validation of frontal near-infrared spectroscopy as noninvasive bedside monitoring for regional cerebral blood flow in brain-injured patients. Neurosurgical focus. 2012;32(2):E2. 
19. Damian MS, Schlosser R. Bilateral near infrared spectroscopy in space-occupying middle cerebral artery stroke. Neurocritical care. 2007;6(3):165-73.

20. Kaesmacher J, Huber T, Lehm M, Zimmer C, Bernkopf K, Wunderlich S, et al. Isolated Striatocapsular Infarcts after Endovascular Treatment of Acute Proximal Middle Cerebral Artery Occlusions: Prevalence, Enabling Factors, and Clinical Outcome. Frontiers in neurology. 2017;8:272.

21. Shin HK, Nishimura M, Jones PB, Ay H, Boas DA, Moskowitz MA, et al. Mild induced hypertension improves blood flow and oxygen metabolism in transient focal cerebral ischemia. Stroke. 2008;39(5):1548-55.

\section{Tables and Figures}

\section{Table 1. Factors influencing $\mathrm{rSO}_{2}$ values}

Contamination form hair and skin

Sweating

Skull thickness

Extracranial circulation

$\mathrm{O}_{2}$ extraction of brain tissue (e.g.: reduced $\mathrm{O}_{2}$ extraction of infarcted or oedematous territory)

Blood pressure

Peripheral oxygen saturation

Haemoglobin concentration in blood

Level of consciousness 
Table 2. Patient characteristics

\begin{tabular}{|c|c|c|c|c|c|}
\hline & Patient 1 & Patient 2 & Patient 3 & Patient 4 & Patient 5 \\
\hline Sex & female & male & male & female & female \\
\hline Age & 80 & 67 & 63 & 66 & 78 \\
\hline Vessel territory & left MCA & left ICA & left MCA & left MCA & left MCA \\
\hline $\begin{array}{l}\text { LKW to treatment } \\
\text { time (min) }\end{array}$ & 128 & 97 & 200 & 245 & 228 \\
\hline Hypertension & yes & yes & yes & yes & yes \\
\hline Hyperlipidaemia & no & yes & yes & yes & yes \\
\hline Diabetes mellitus & no & no & no & no & no \\
\hline Atrial fibrillation & no & no & no & no & no \\
\hline $\begin{array}{l}\text { Ischaemic heart } \\
\text { disease }\end{array}$ & yes & no & yes & no & yes \\
\hline Smoking & no & no & yes & yes & yes \\
\hline Haemoglobin (g/l) & 142 & 140 & 139 & 153 & 121 \\
\hline $\begin{array}{l}\text { Large vessel } \\
\text { occlusion }\end{array}$ & left M2 & left ICA & left M1 & 0 & $\begin{array}{l}\text { right ICA } \\
\text { (chronic) }\end{array}$ \\
\hline Collateral score & good & good & intermediate & not applicable & $\begin{array}{c}\text { not } \\
\text { applicable }\end{array}$ \\
\hline Stroke subtype & $\mathrm{CE}$ & LAA & $\mathrm{CE}$ & $\begin{array}{c}\text { SVD } \\
\text { (striatocapsular } \\
\text { infarct) }\end{array}$ & $\mathrm{CE}$ \\
\hline NIHSS baseline & 14 & 15 & 17 & 7 & 9 \\
\hline NIHSS 24-hour & 9 & 12 & 12 & 10 & 4 \\
\hline NIHSS discharge & 4 & 9 & 8 & 10 & 1 \\
\hline mRS 3 months & 2 & 2 & 1 & 3 & 1 \\
\hline
\end{tabular}

Abbreviations: CE: cardioembolic, ICA: internal carotid artery, LAA: large-artery atherosclerosis, LKW: last known well, MCA: middle cerebral artery, mRS: modified Rankin score, NIHSS: National Institutes of Health Stroke Scale, SVD: small vessel disease, VA: vertebral artery. 
Table 3. Relevant findings of previous studies with NIRS

\begin{tabular}{|c|c|c|}
\hline Study & Timing of monitoring & Findings \\
\hline \multirow{3}{*}{ Ritzenthaler et al. (4) } & \multirow{3}{*}{$\begin{array}{l}\text { first } 24 \text { hours, including } \\
\text { thrombectomy }\end{array}$} & $\begin{array}{l}\text { lower absolute } \mathrm{rSO}_{2} \text { values } \\
\text { above the affected } \\
\text { hemisphere in all patients } \\
(\mathrm{n}=17)\end{array}$ \\
\hline & & $\begin{array}{l}\text { no significant relationship } \\
\text { between initial ipsilateral } \\
\mathrm{rSO}_{2} \text { and collateral } \\
\text { circulation }\end{array}$ \\
\hline & & $\begin{array}{l}\text { correlation was found } \\
\text { between } \mathrm{rSO}_{2} \text { and } \mathrm{MRI} \\
\text { parameters }\left(\mathrm{MTT} \text { and } \mathrm{T}_{\max } \text { ) }\right.\end{array}$ \\
\hline \multirow{3}{*}{ Hametner et al. (3) } & \multirow{3}{*}{$\begin{array}{l}\text { during thrombectomy }+6 \\
\text { hours or time to extubation }\end{array}$} & $\begin{array}{l}\text { median } \mathrm{IH} \Delta \mathrm{rSO}_{2} \text { at the end of } \\
\text { thrombectomy was } \\
\text { significantly lower in patients } \\
\text { who died by } 90 \text { days }\end{array}$ \\
\hline & & $\begin{array}{l}\text { variability in } \mathrm{rSO}_{2} \text { were lower } \\
\text { in patients with mRS score } 3 \text { - } \\
6 \text { at 90-days }\end{array}$ \\
\hline & & $\begin{array}{l}\text { significant association } \\
\text { between changes in MAP and } \\
\mathrm{rSO}_{2}\end{array}$ \\
\hline \multirow{3}{*}{ Damian and Schlosser (19) } & \multirow{3}{*}{$\begin{array}{l}\text { subacute phase ( } 12 \mathrm{~h} \text { to } 4 \\
\text { days after stroke) }\end{array}$} & $\begin{array}{l}22 / 24 \text { patients had higher } \\
\text { absolute } \mathrm{rSO}_{2} \text { above the } \\
\text { ipsilateral frontal area }\end{array}$ \\
\hline & & $\begin{array}{l}\text { good clinical outcome when } \\
\text { average } \mathrm{IH} \Delta \mathrm{rSO}_{2} \text { values } \\
\text { increased }\end{array}$ \\
\hline & & $\begin{array}{l}\text { progression of brain oedema } \\
\text { and unfavourable } \mathrm{rSO}_{2} \\
\text { changes were reversible by } \\
\text { therapeutic interventions } \\
\text { (e.g.: hemicraniectomy) }\end{array}$ \\
\hline \multirow{2}{*}{$\begin{array}{l}\text { Moreau et al. (multichannel } \\
\text { monitoring) (12) }\end{array}$} & \multirow{2}{*}{$\begin{array}{l}\text { acute phase ( } 9 \text { hours } \geq \text { after } \\
\text { symptom onset) }\end{array}$} & $\begin{array}{l}\text { at least one ipsilateral region } \\
\text { showed reduced } \mathrm{rSO}_{2} \\
\text { compared to unaffected side }\end{array}$ \\
\hline & & $\begin{array}{l}\mathrm{rSO}_{2} \text { values were } \\
\text { significantly higher after } \\
\text { haemorrhagic transformation }\end{array}$ \\
\hline $\begin{array}{l}\text { Rummel et al. (multichannel } \\
\text { monitoring) (8) }\end{array}$ & $\begin{array}{l}\text { transient balloon occlusion of } \\
\text { cerebral arteries }\end{array}$ & $\begin{array}{l}\text { different } \mathrm{rSO}_{2} \text { changes over } \\
\text { ischaemic core and watershed } \\
\text { areas }\end{array}$ \\
\hline
\end{tabular}

Abbreviations: $\mathrm{IH} \Delta \mathrm{rSO} 2$ : interhemispheric $\mathrm{rSO}_{2}$ difference, MAP: mean arterial pressure, MRI: magnetic resonance imaging, mRS: modified Rankin scale, MTT: mean transit time, $\mathrm{T}_{\max }$ : time-to-maximum, $\mathrm{rSO}_{2}$ : regional oxygen saturation. 
Figure 1. CT and MRI scans of patients approximately 24 hours after thrombolysis. a) Diffusion-weighted imaging (DWI) scan of Patient 1, showing left MCA territory cortical ischaemia. b) DWI scan of Patient 2 shows a similar brain infarct. c) Non-contrast CT (NCCT) scan of Patient 3 after thrombectomy. The infarct mainly involves the left basal ganglia and internal capsule. d) NCCT of Patient 4 showing slight hypodensity in the left corona radiata (striatocapsular infarct). e) DWI scan of patient 5 shows a left MCA territory infarct. f) MRA-TOF reconstruction of Patient 5 demonstrating enlarged left ICA and MCA.

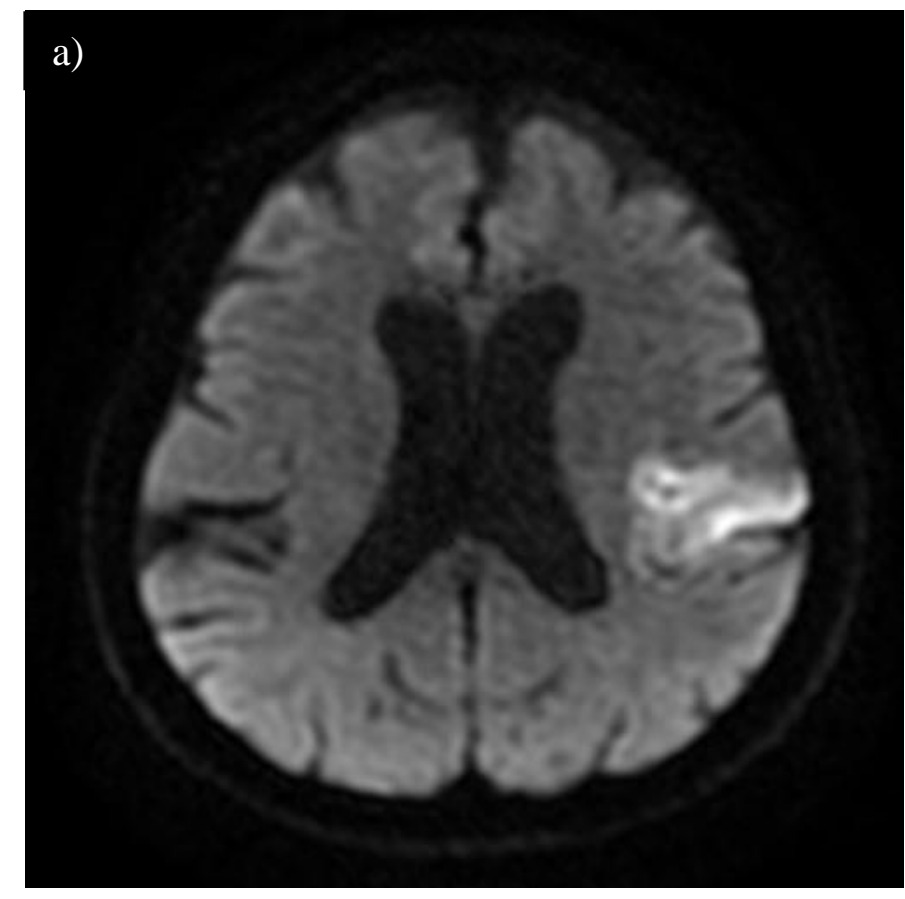

b) 

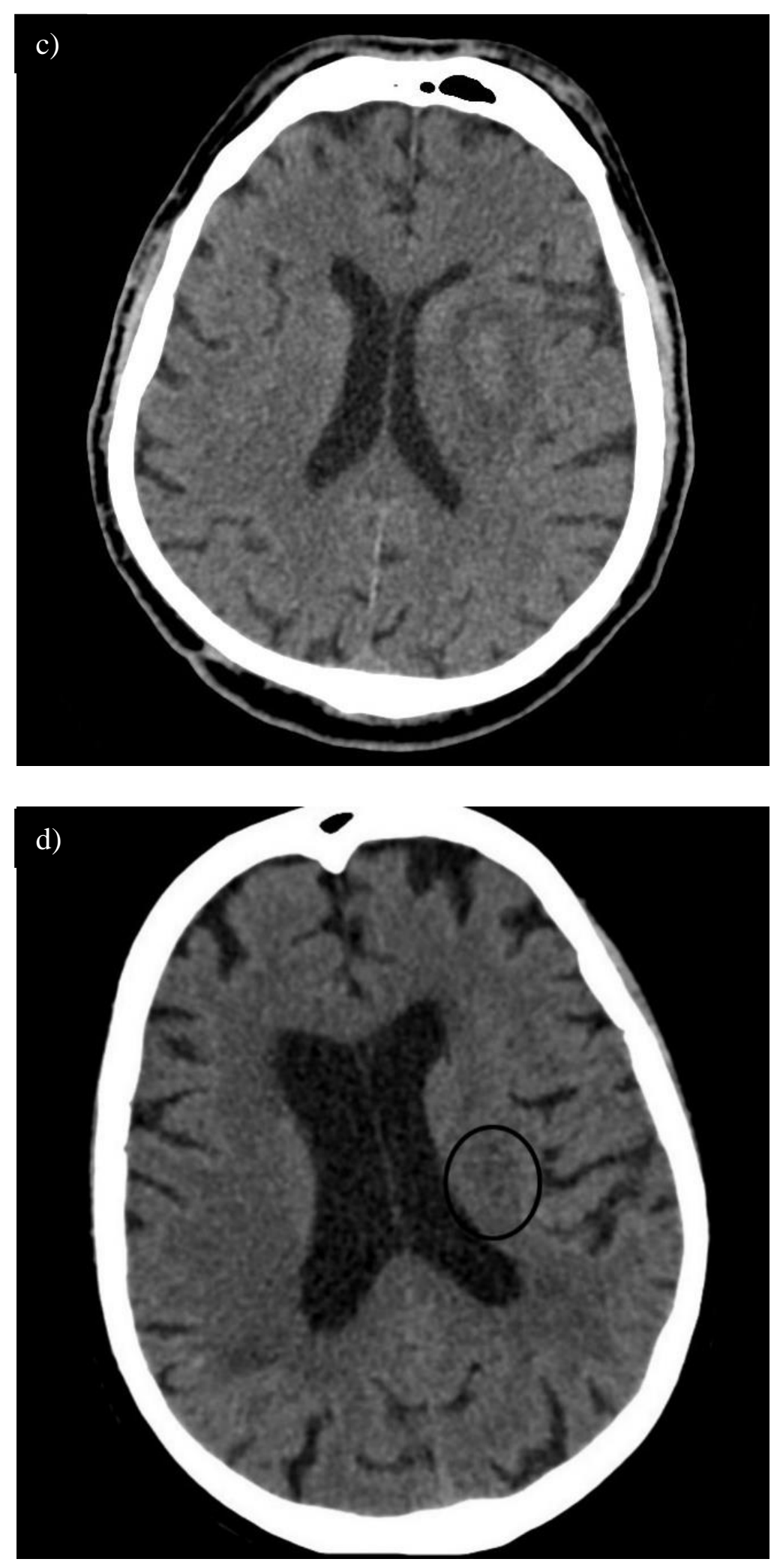

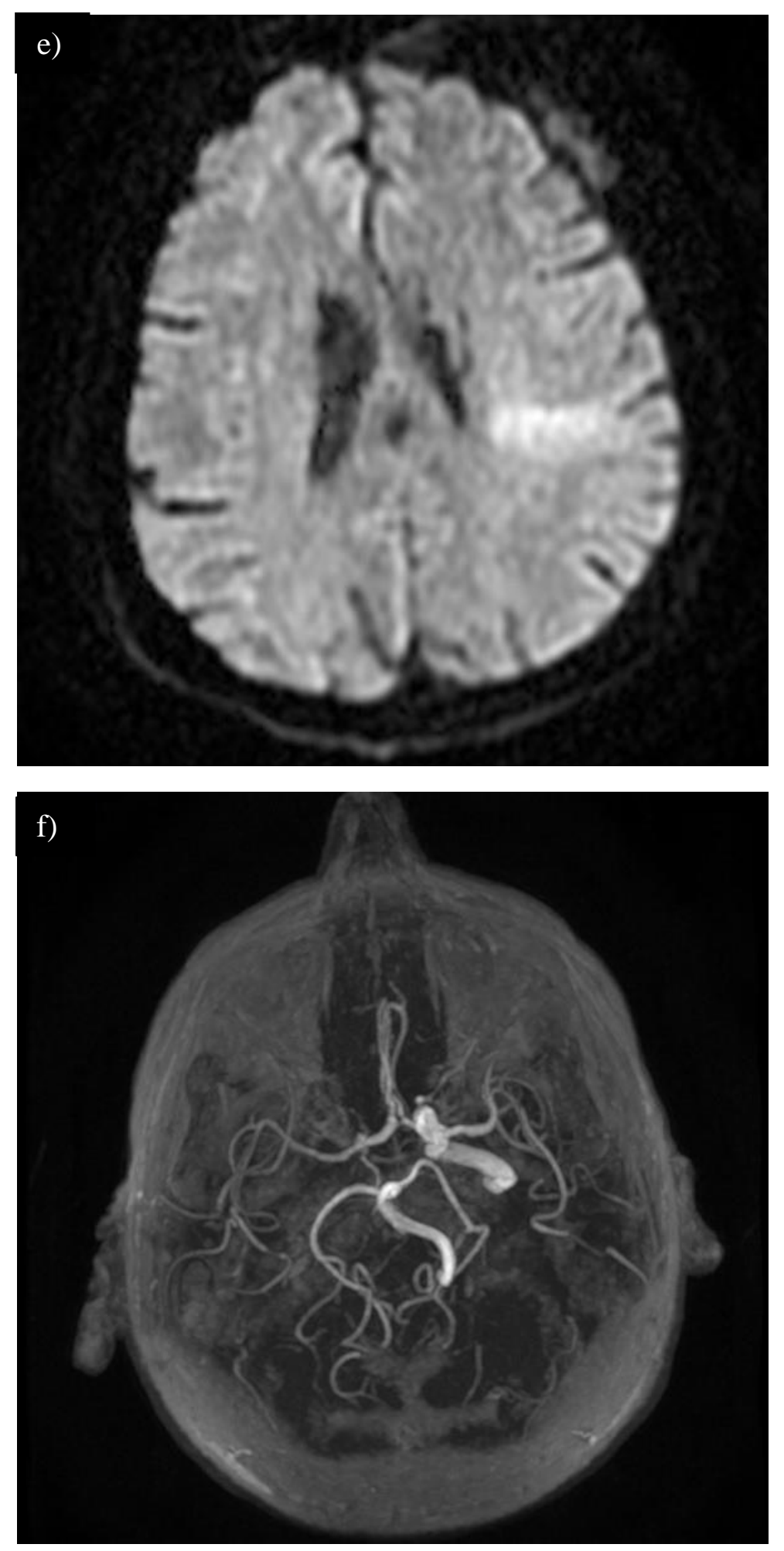


\section{Supplementary material}

NIRS data from Patient 1.

\begin{tabular}{|l|c|c|c|}
\hline \multicolumn{1}{|c|}{ Time } & $\begin{array}{c}\text { Affected side } \\
\mathbf{r S O}_{\mathbf{2}}(\boldsymbol{\%})\end{array}$ & $\begin{array}{c}\text { Unaffected side } \mathbf{r S O}_{2} \\
(\mathbf{\%})\end{array}$ & IH $\mathbf{H} \mathbf{r S O}_{\mathbf{2}}(\boldsymbol{\%})$ \\
\hline Before thrombolysis & 63 & 64 & -1 \\
\hline 1 h post thrombolysis & 63 & 63 & 0 \\
\hline 6 h post thrombolysis & 60 & 61 & -1 \\
\hline 12 h post thrombolysis & 59 & 59 & 0 \\
\hline 18 h post thrombolysis & 61 & 63 & -2 \\
\hline 24 h post thrombolysis & 61 & 62 & -1 \\
\hline Average & 60,80 & 61,60 & $-0,80$ \\
\hline
\end{tabular}

$\mathrm{rSO}_{2}(\%)$ trends of Patient 1.

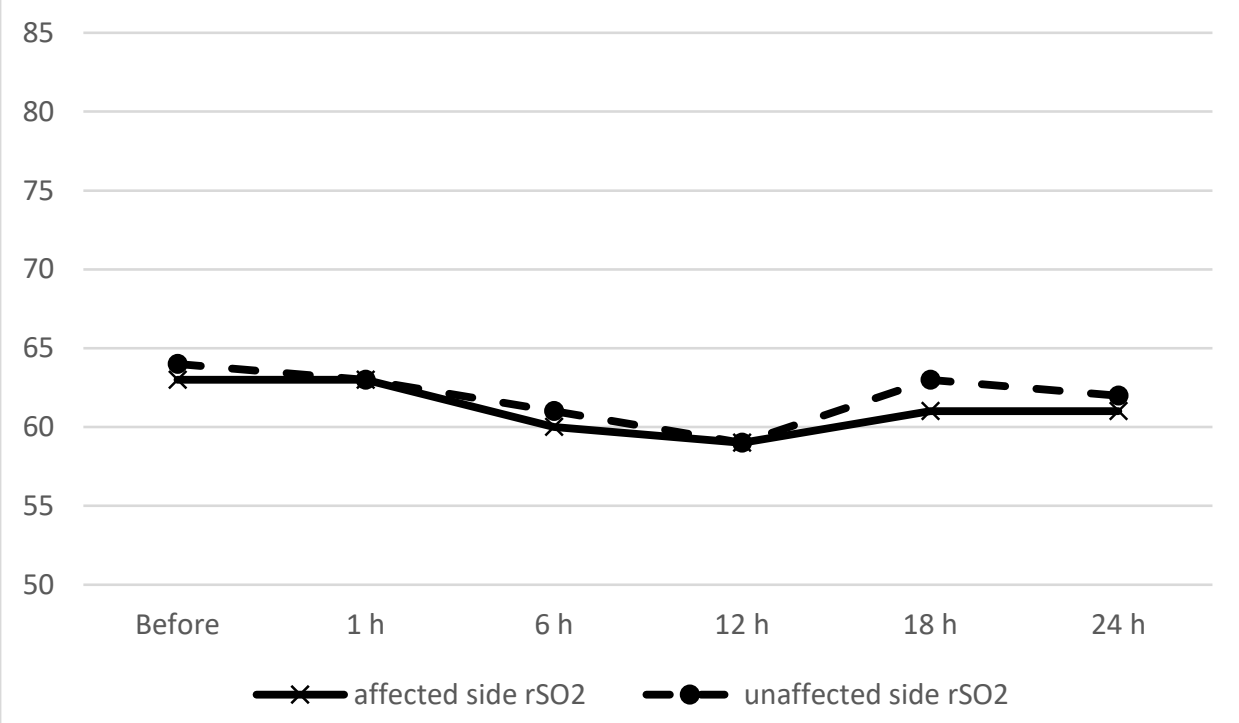

IH $\Delta \mathrm{rSO}_{2}(\%)$ trend of Patient 1.

$\mathrm{IH} \Delta \mathrm{rSO}_{2}$

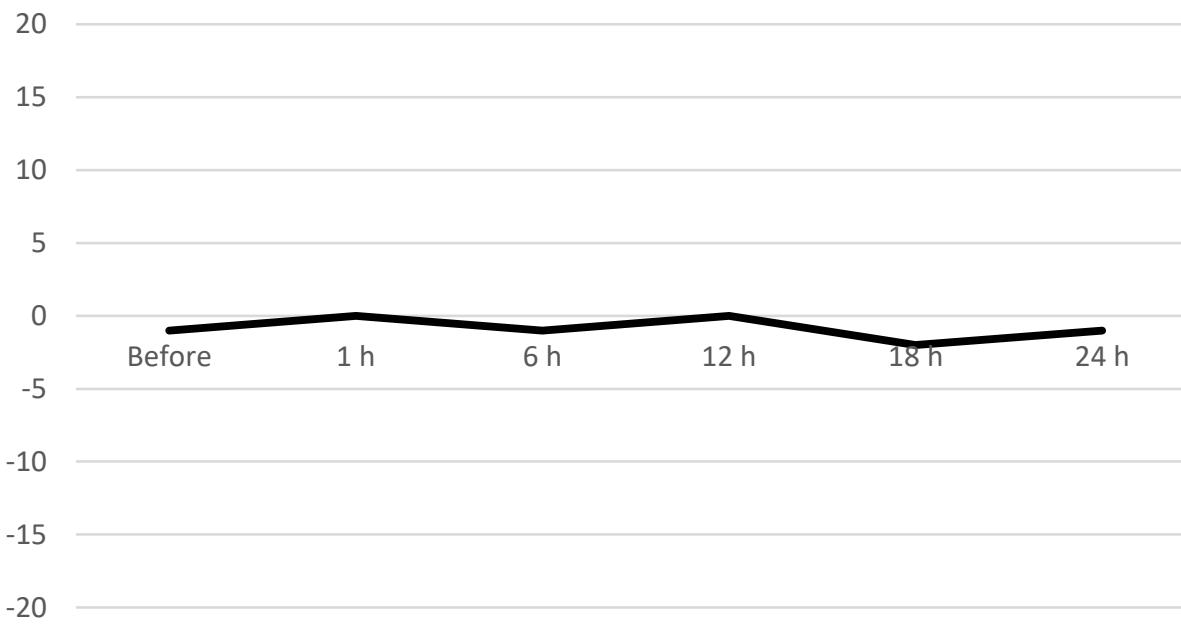


NIRS data from Patient 2.

\begin{tabular}{|l|c|c|c|}
\hline \multicolumn{1}{|c|}{ Time } & $\begin{array}{c}\text { Affected side } \\
\mathbf{r S O}_{\mathbf{2}}(\boldsymbol{\%})\end{array}$ & $\begin{array}{c}\text { Unaffected side } \mathbf{r S O}_{\mathbf{2}} \\
(\mathbf{\%})\end{array}$ & $\mathbf{I H \Delta \mathbf { r S O } _ { \mathbf { 2 } } ( \boldsymbol { \% } )}$ \\
\hline Before thrombolysis & 67 & 63 & 4 \\
\hline 1 h post thrombolysis & 69 & 64 & 5 \\
\hline 6 h post thrombolysis & 73 & 71 & 2 \\
\hline 12 h post thrombolysis & 74 & 73 & 1 \\
\hline 18 h post thrombolysis & 63 & 62 & 1 \\
\hline 24 h post thrombolysis & 70 & 65 & 5 \\
\hline Average & 69,33 & 66,33 & 3 \\
\hline
\end{tabular}

$\mathrm{rSO}_{2}(\%)$ trends of Patient 2.

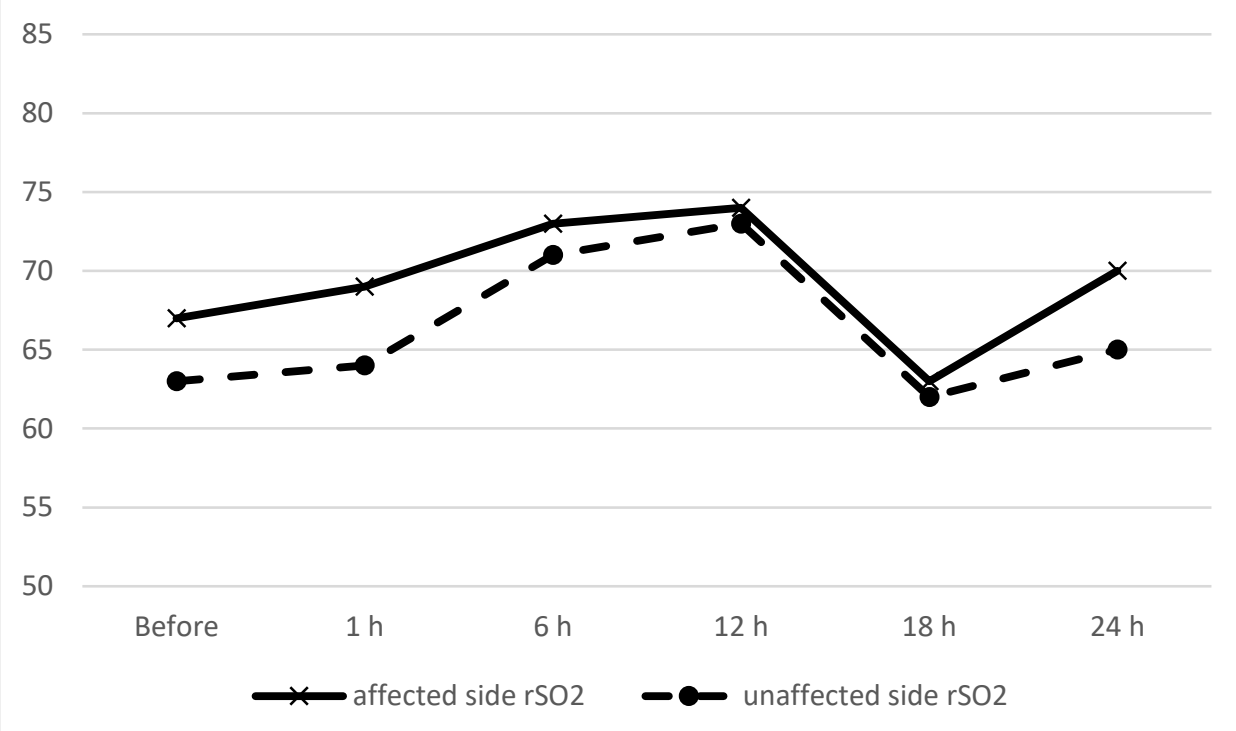

IH $\Delta \mathrm{rSO}_{2}(\%)$ trend of Patient 2.

$\mathrm{IH} \Delta \mathrm{rSO}_{2}$

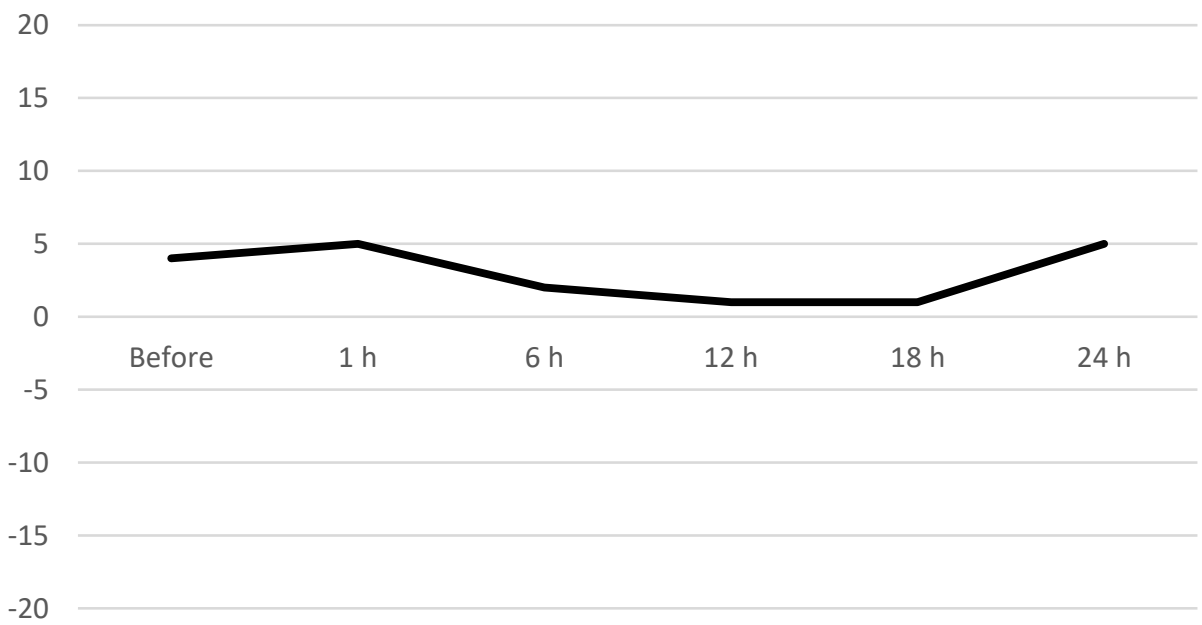


NIRS data from Patient 3.

\begin{tabular}{|l|c|c|c|}
\hline \multicolumn{1}{|c|}{ Time } & $\begin{array}{c}\text { Affected side } \\
\mathbf{r S O}_{\mathbf{2}}(\boldsymbol{\%})\end{array}$ & $\begin{array}{c}\text { Unaffected side } \mathbf{r S O}_{\mathbf{2}} \\
(\mathbf{\%})\end{array}$ & $\mathbf{I H \Delta \mathbf { r S O } _ { \mathbf { 2 } } ( \boldsymbol { \% } )}$ \\
\hline Before thrombolysis & 55 & 63 & -8 \\
\hline 1 h post thrombolysis & 54 & 61 & -7 \\
\hline 6 h post thrombolysis & 65 & 66 & -1 \\
\hline 12 h post thrombolysis & 63 & 62 & 1 \\
\hline 18 h post thrombolysis & 62 & 58 & 4 \\
\hline 24 h post thrombolysis & 61 & 60 & 1 \\
\hline Average & 60,00 & 61,67 & $-1,67$ \\
\hline
\end{tabular}

$\mathrm{rSO}_{2}(\%)$ trends of Patient 3.

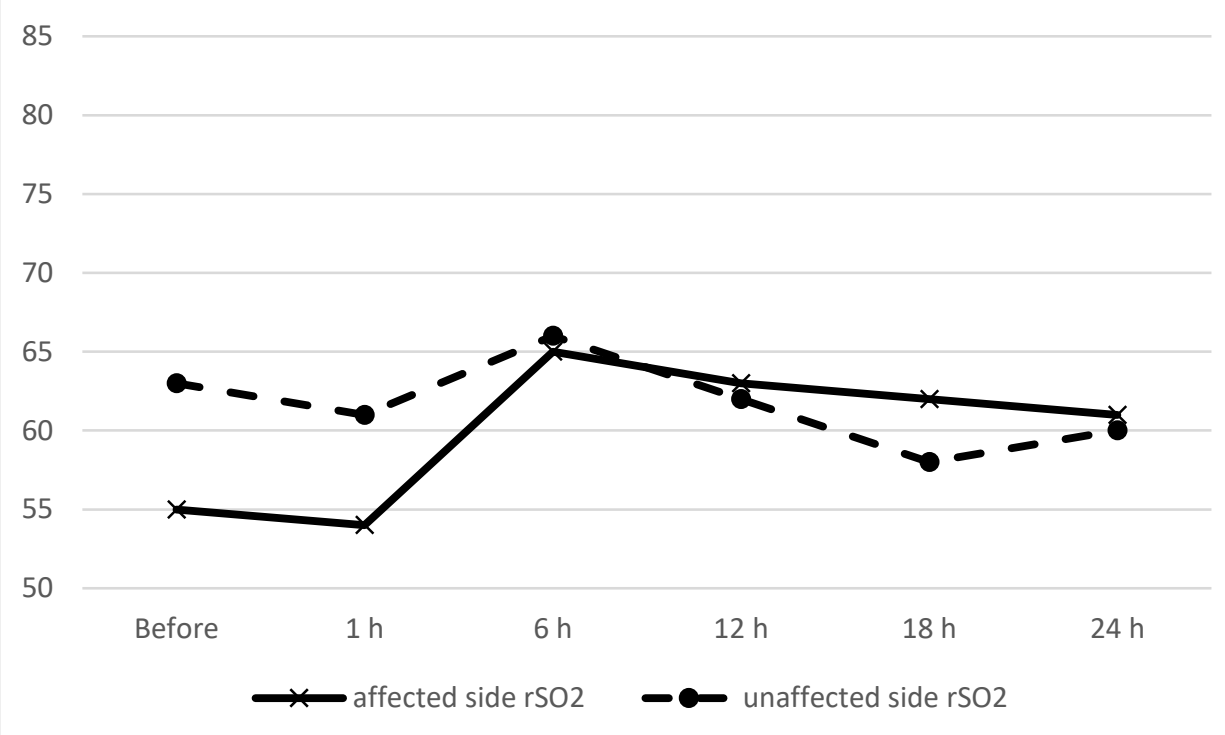

IH $\Delta \mathrm{rSO}_{2}(\%)$ trend of Patient 3.

$\mathrm{IH} \Delta \mathrm{rSO}_{2}$

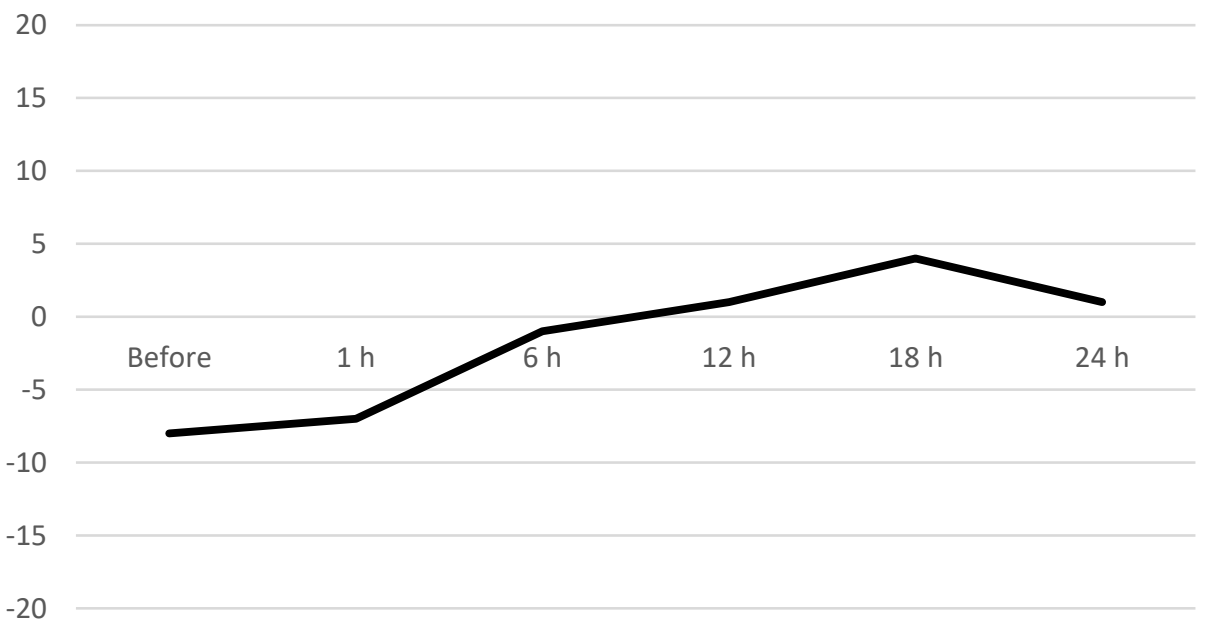


NIRS data from Patient 4.

\begin{tabular}{|l|c|c|c|}
\hline \multicolumn{1}{|c|}{ Time } & $\begin{array}{c}\text { Affected side } \\
\mathbf{r S O}_{\mathbf{2}}(\boldsymbol{\%})\end{array}$ & $\begin{array}{c}\text { Unaffected side } \mathbf{r S O}_{\mathbf{2}} \\
(\mathbf{\%})\end{array}$ & $\mathbf{I H \Delta \mathbf { r S O } _ { \mathbf { 2 } } ( \boldsymbol { \% } )}$ \\
\hline Before thrombolysis & 69 & 61 & 8 \\
\hline 1 h post thrombolysis & 78 & 70 & 8 \\
\hline 6 h post thrombolysis & 68 & 62 & 6 \\
\hline 12 h post thrombolysis & 69 & 71 & -2 \\
\hline 18 h post thrombolysis & 70 & 71 & -1 \\
\hline 24 h post thrombolysis & 73 & 75 & -2 \\
\hline Average & 71,17 & 68,33 & 2,83 \\
\hline
\end{tabular}

$\mathrm{rSO}_{2}(\%)$ trends of Patient 4.

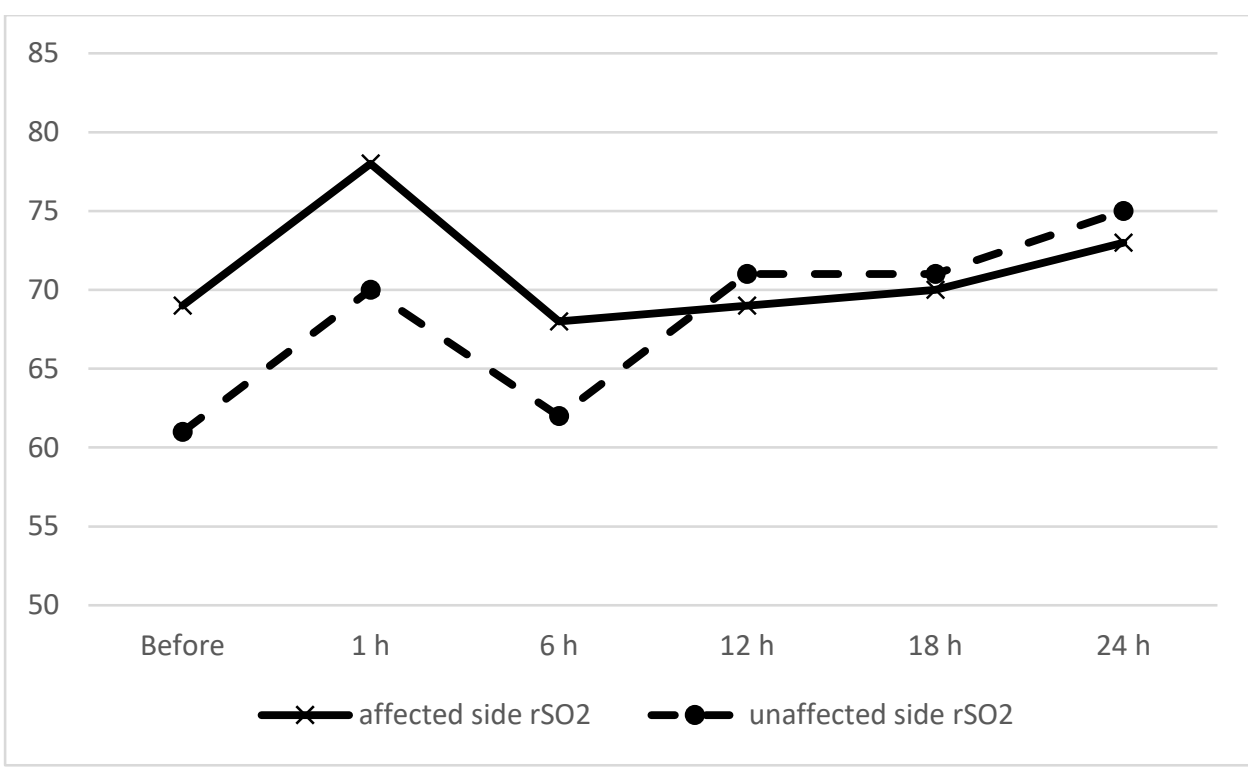

IH $\Delta \mathrm{rSO}_{2}(\%)$ trend of Patient 4.

\section{$\mathrm{IH} \Delta \mathrm{rSO}_{2}$}

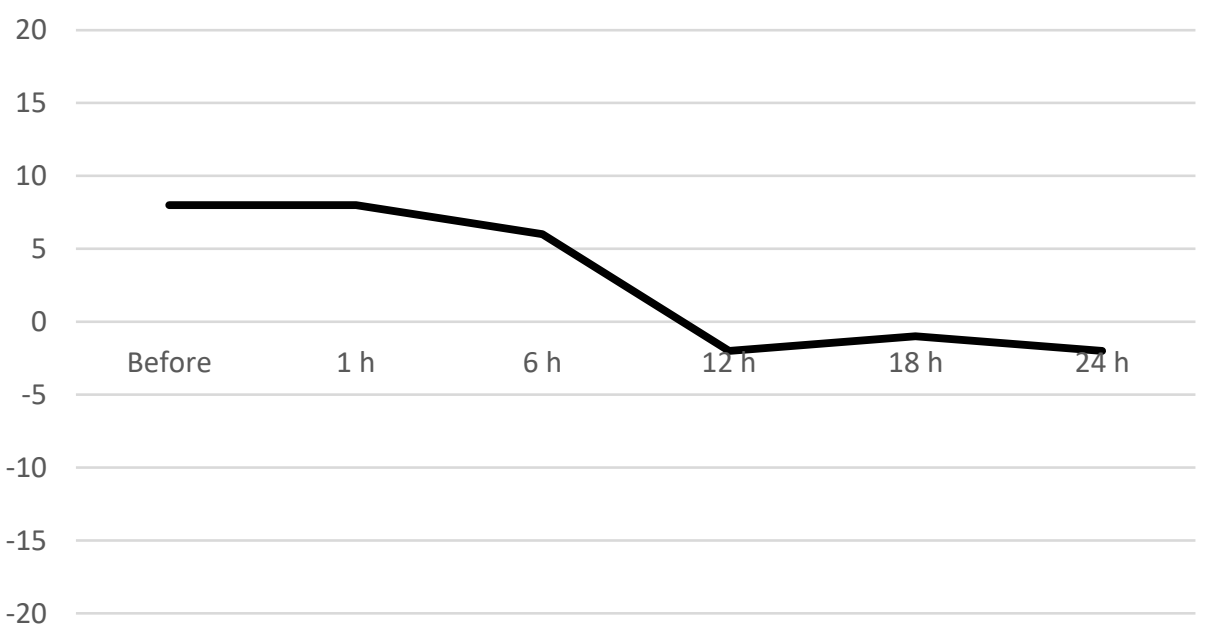


NIRS data from Patient 5.

\begin{tabular}{|l|c|c|c|}
\hline \multicolumn{1}{|c|}{ Time } & $\begin{array}{c}\text { Affected side } \\
\mathbf{r S O}_{\mathbf{2}}(\boldsymbol{\%})\end{array}$ & $\begin{array}{c}\text { Unaffected side } \\
\mathbf{r S O}_{\mathbf{2}}(\boldsymbol{\%})\end{array}$ & IH $\mathbf{\Delta r S O}$ (\%) \\
\hline Before thrombolysis & 82 & 69 & 13 \\
\hline 1 h post thrombolysis & 86 & 68 & 18 \\
\hline 6 h post thrombolysis & 78 & 63 & 15 \\
\hline 12 h post thrombolysis & 77 & 60 & 17 \\
\hline 18 h post thrombolysis & 81 & 71 & 10 \\
\hline 24 h post thrombolysis & 77 & 60 & 17 \\
\hline Average & 80,17 & 65,17 & 15,00 \\
\hline
\end{tabular}

$\mathrm{rSO}_{2}(\%)$ trends of Patient 5.

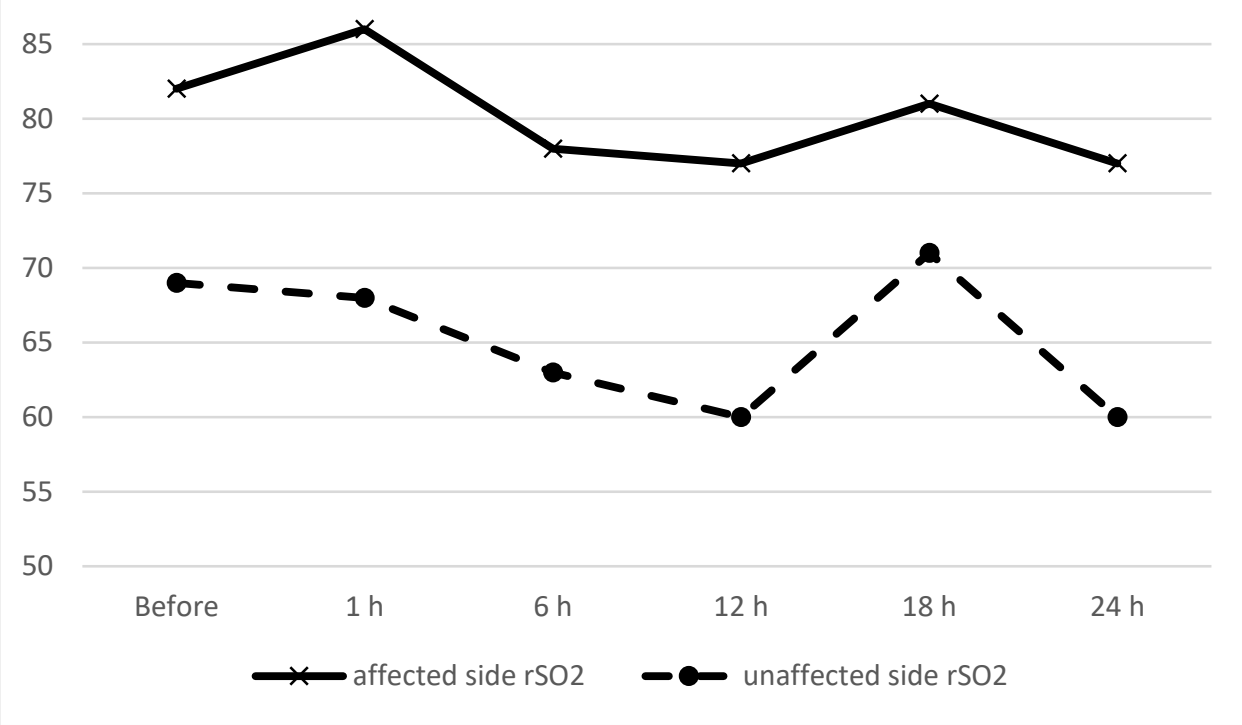

IH $\Delta \mathrm{rSO}_{2}(\%)$ trend of Patient 5.

$\mathrm{IH} \Delta \mathrm{rSO} 2$

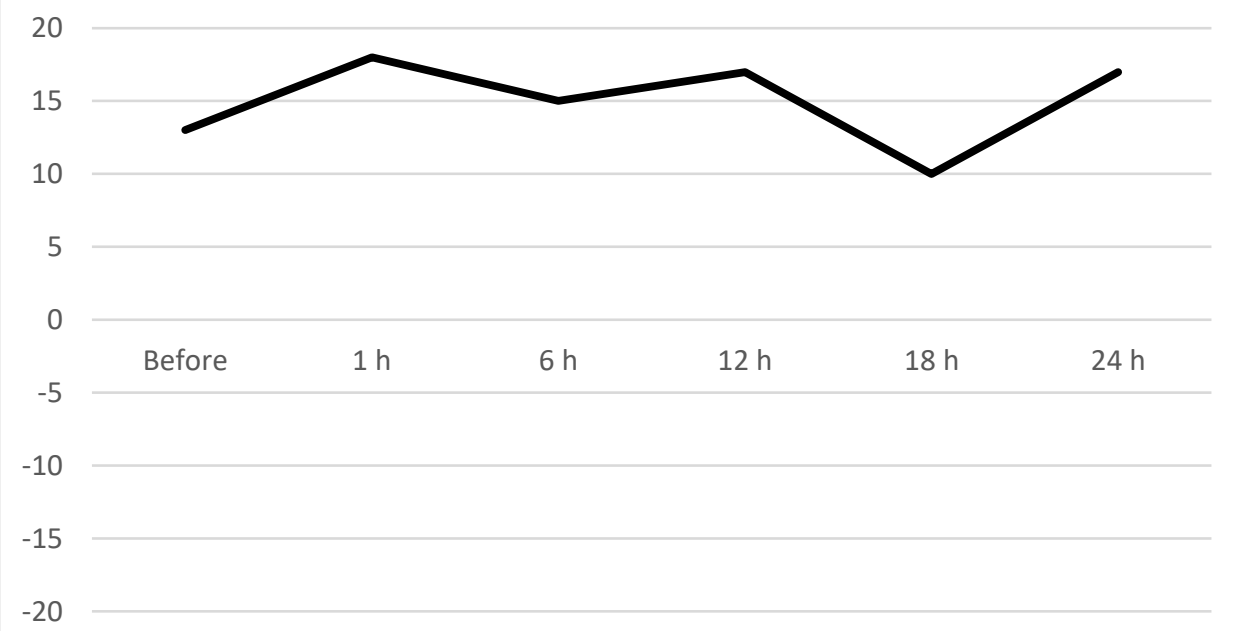


Data and graphs on $\mathrm{rSO}_{2}$ variability

a) Ipsilateral side

\begin{tabular}{|l|c|c|c|}
\hline \multicolumn{1}{|c|}{ Time } & $\begin{array}{c}\mathbf{r S O}_{2} \text { max. (\%) } \\
\text { including Patient 5 }\end{array}$ & $\begin{array}{c}\text { rSO }_{2} \text { max. (\%) not } \\
\text { including Patient 5 }\end{array}$ & rSO $_{\mathbf{2}}$ min. (\%) \\
\hline Before thrombolysis & 82 & 69 & 55 \\
\hline 1 h post thrombolysis & 86 & 78 & 54 \\
\hline 6 h post thrombolysis & 78 & 73 & 60 \\
\hline 12 h post thrombolysis & 77 & 74 & 59 \\
\hline 18 h post thrombolysis & 81 & 70 & 61 \\
\hline 24 h post thrombolysis & 77 & 73 & 61 \\
\hline
\end{tabular}

$\mathrm{rSO}_{2}$ max-min difference (\%) on affected side including Patient 5
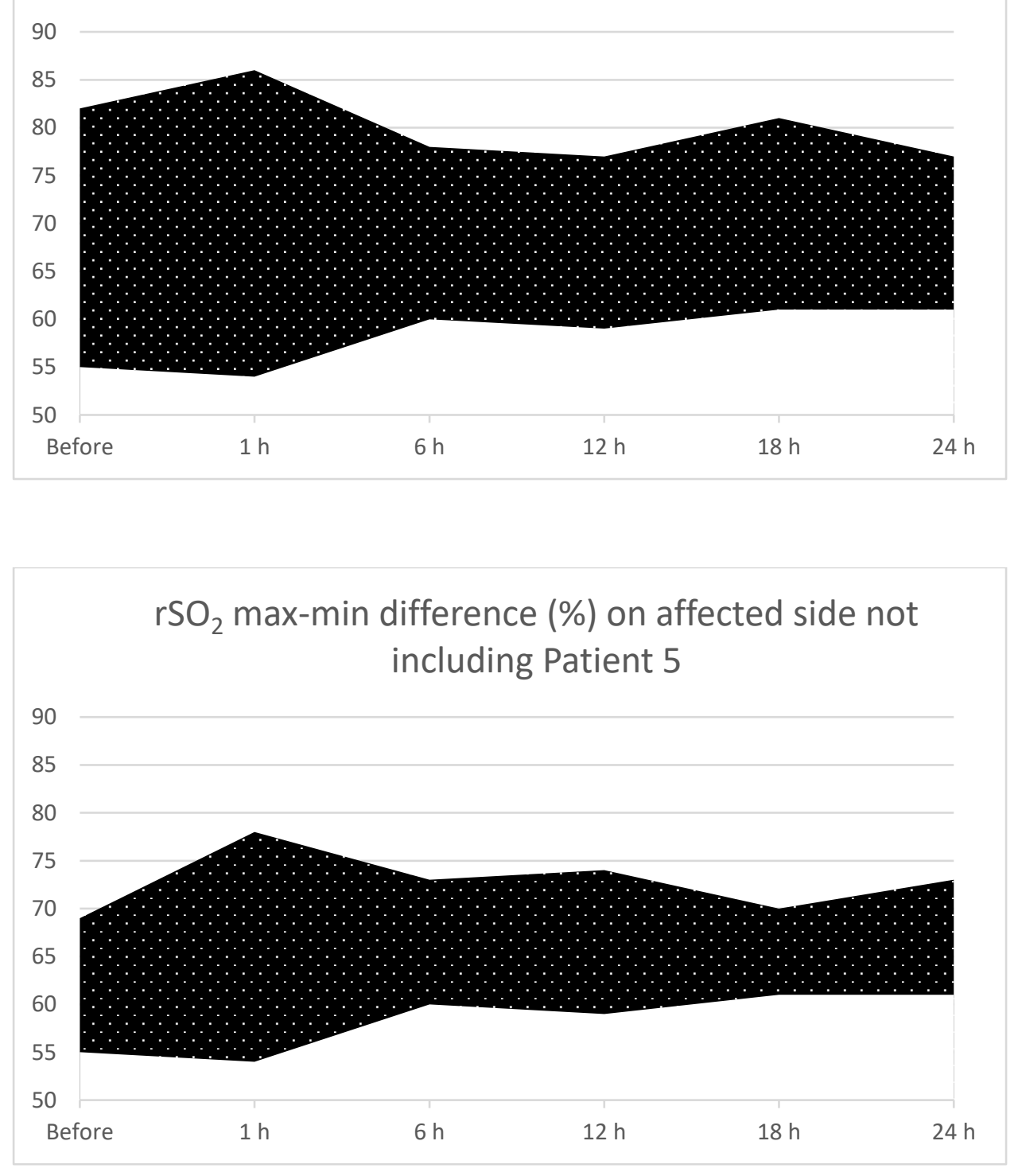
b) Contralateral side

\begin{tabular}{|l|c|c|}
\hline \multicolumn{1}{|c|}{ Time } & rSO $_{2}$ max. (\%) & rSO $_{\mathbf{2}}$ min. (\%) \\
\hline Before thrombolysis & 69 & 61 \\
\hline 1 h post thrombolysis & 70 & 61 \\
\hline 6 h post thrombolysis & 71 & 61 \\
\hline 12 h post thrombolysis & 73 & 60 \\
\hline 18 h post thrombolysis & 71 & 58 \\
\hline 24 h post thrombolysis & 75 & 60 \\
\hline
\end{tabular}

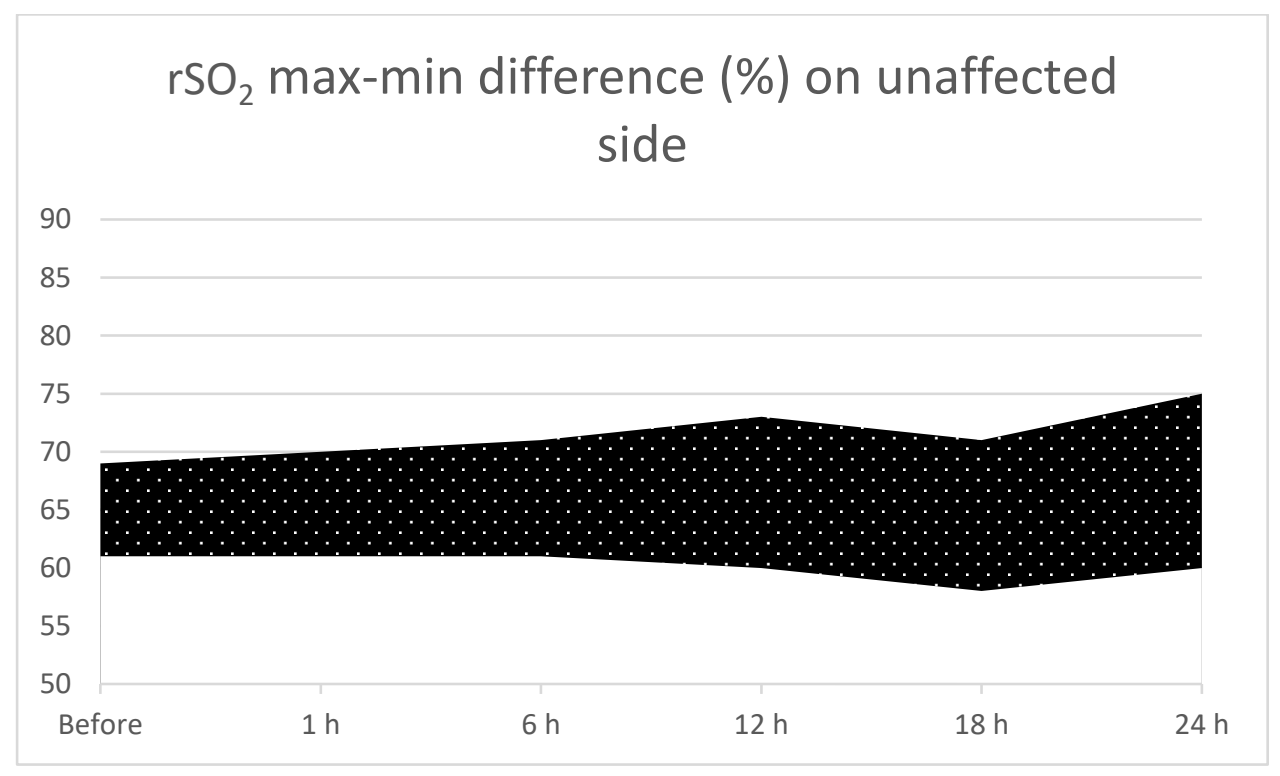

